\title{
Detection of Potential Induced Degradation in c-Si PV Panels Using Electrical Impedance Spectroscopy
}

Oprea, Matei-Ion; Spataru, Sergiu; Sera, Dezso; Basu, Ronni; Andersen, Anders R.; Poulsen, Peter Behrensdorff

\section{Publication date:}

2016

Document Version

Publisher's PDF, also known as Version of record

Link back to DTU Orbit

Citation $(A P A)$ :

Oprea, M., Spataru, S., Sera, D., Basu, R., Andersen, A. R., \& Poulsen, P. B. (2016). Detection of Potential Induced Degradation in c-Si PV Panels Using Electrical Impedance Spectroscopy. Poster session presented at 42nd IEEE Photovoltaic Specialists Conference, New Orleans, Louisiana, United States.

\section{General rights}

Copyright and moral rights for the publications made accessible in the public portal are retained by the authors and/or other copyright owners and it is a condition of accessing publications that users recognise and abide by the legal requirements associated with these rights.

- Users may download and print one copy of any publication from the public portal for the purpose of private study or research.

- You may not further distribute the material or use it for any profit-making activity or commercial gain

- You may freely distribute the URL identifying the publication in the public portal 


\section{Detection of Potential Induced Degradation in c-Si PV Panels Using Electrical Impedance Spectroscopy}

\section{Matei Oprea ${ }^{1}$ Sergiu Spataru ${ }^{1}$ Dezso Sera ${ }^{1}$ \\ Peter Poulsen² \\ Sune Thorsteinsson ${ }^{2}$ Ronni Basu ${ }^{3}$ \\ Anders Andersen ${ }^{3}$ \\ Kenn Frederiksen ${ }^{4}$ \\ ${ }^{1}$ Aalborg University \\ ${ }^{2}$ Technical University of Denmark

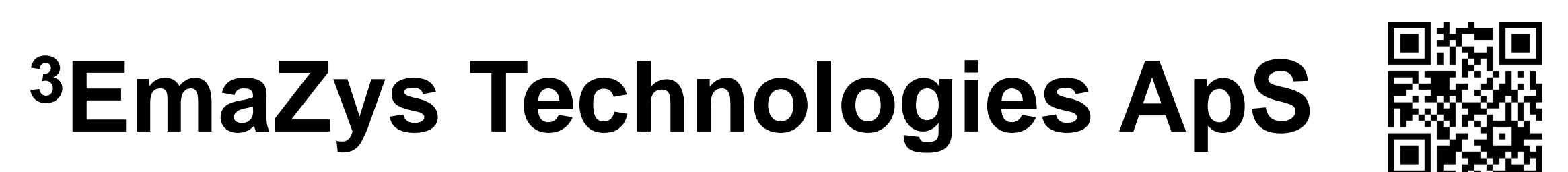

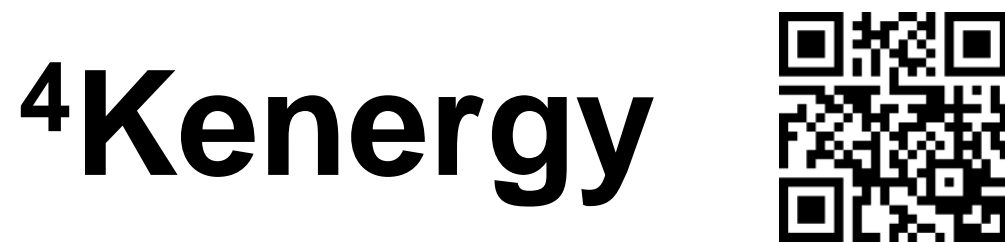

Abstract This work, for the first time, investigates an Impedance Spectroscopy (IS) based method for detecting potential-induced degradation (PID) in crystalline silicon photovoltaic (c-Si PV) panels. The method has been experimentally tested on a set of panels that were confirmed to be affected by PID by using traditional current-voltage (I-V) characterization methods, as well as electroluminescence (EL) imaging. The results confirm the effectiveness of the new approach to detect PID in PV panels.

\section{AC model of the PV panels}

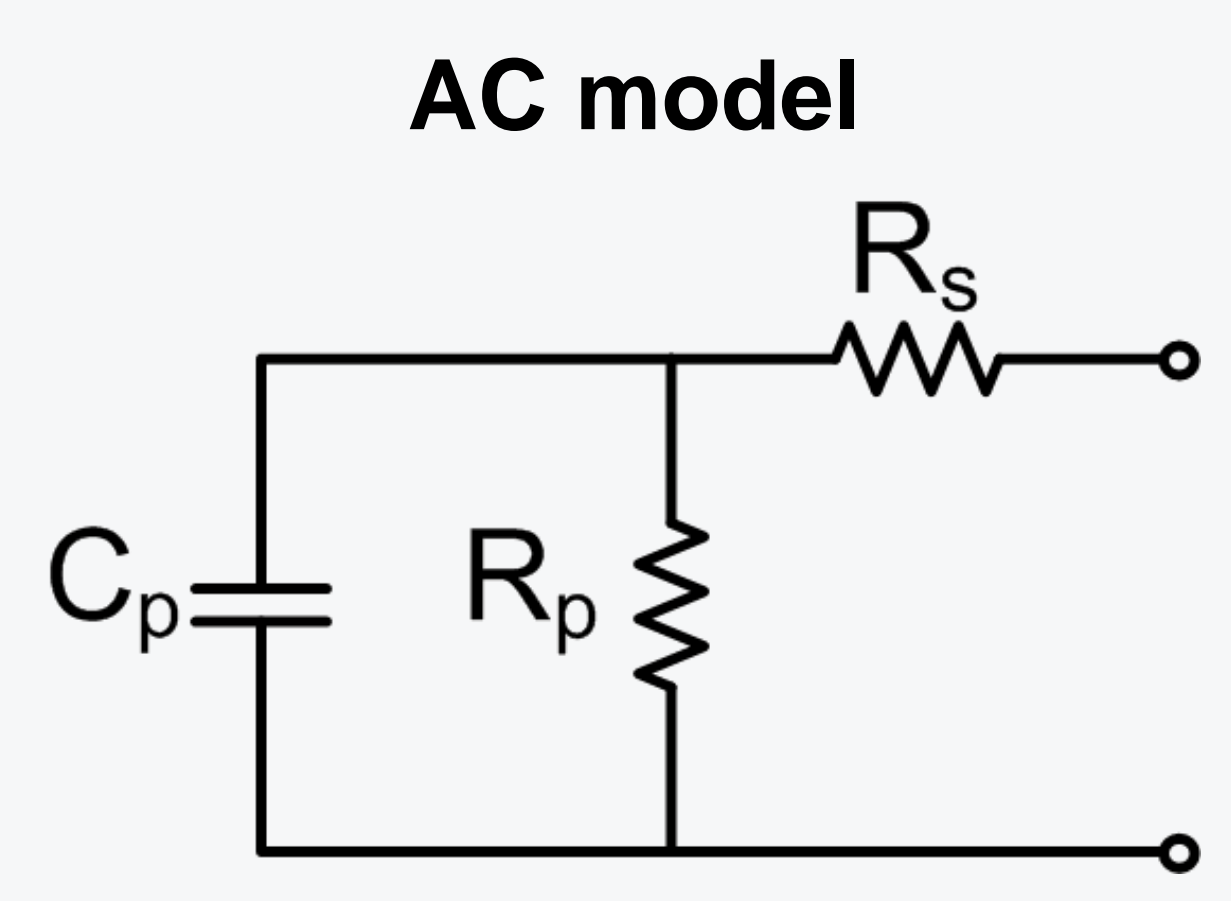

- The equivalent circuit model of PV panel used for the parameter fitting. In this case the emphasis is on the paralle components $C_{p}$ and $R_{p}$.

$$
\begin{array}{r}
Z=R_{s}+\frac{R_{p}}{1+j \omega C_{p} R_{p}} \\
\operatorname{Re}(Z)=R_{s}+\frac{R_{p}}{1+\omega^{2} C_{p}^{2} R_{p}^{2}} \\
\operatorname{Im}(Z)=-\frac{\omega C_{p} R_{p}^{2}}{1+\omega^{2} C_{p}^{2} R_{p}^{2}}
\end{array}
$$

\section{Case study}

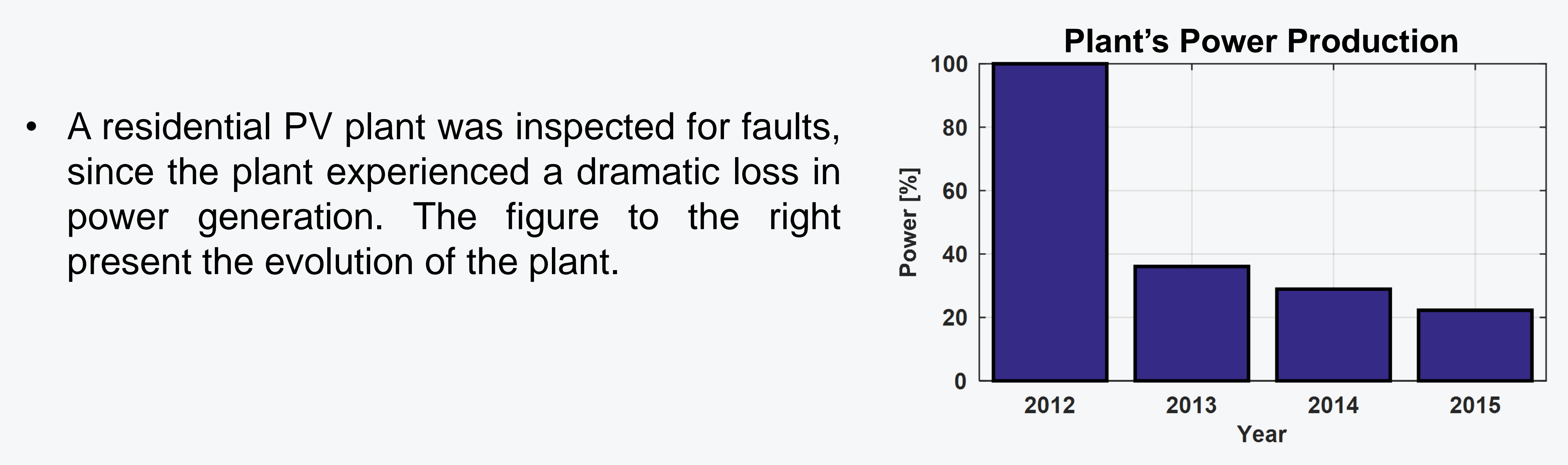

Plant Setup and Modules Positioning

STRING 1

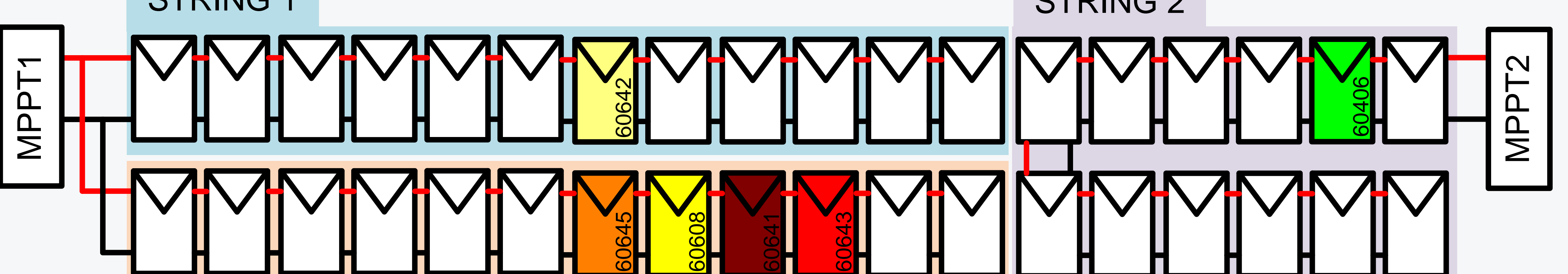

STRING 3

- The best and five worst performing modules were identified in the field using the Z100 PV tester and were selected for laboratory tests.



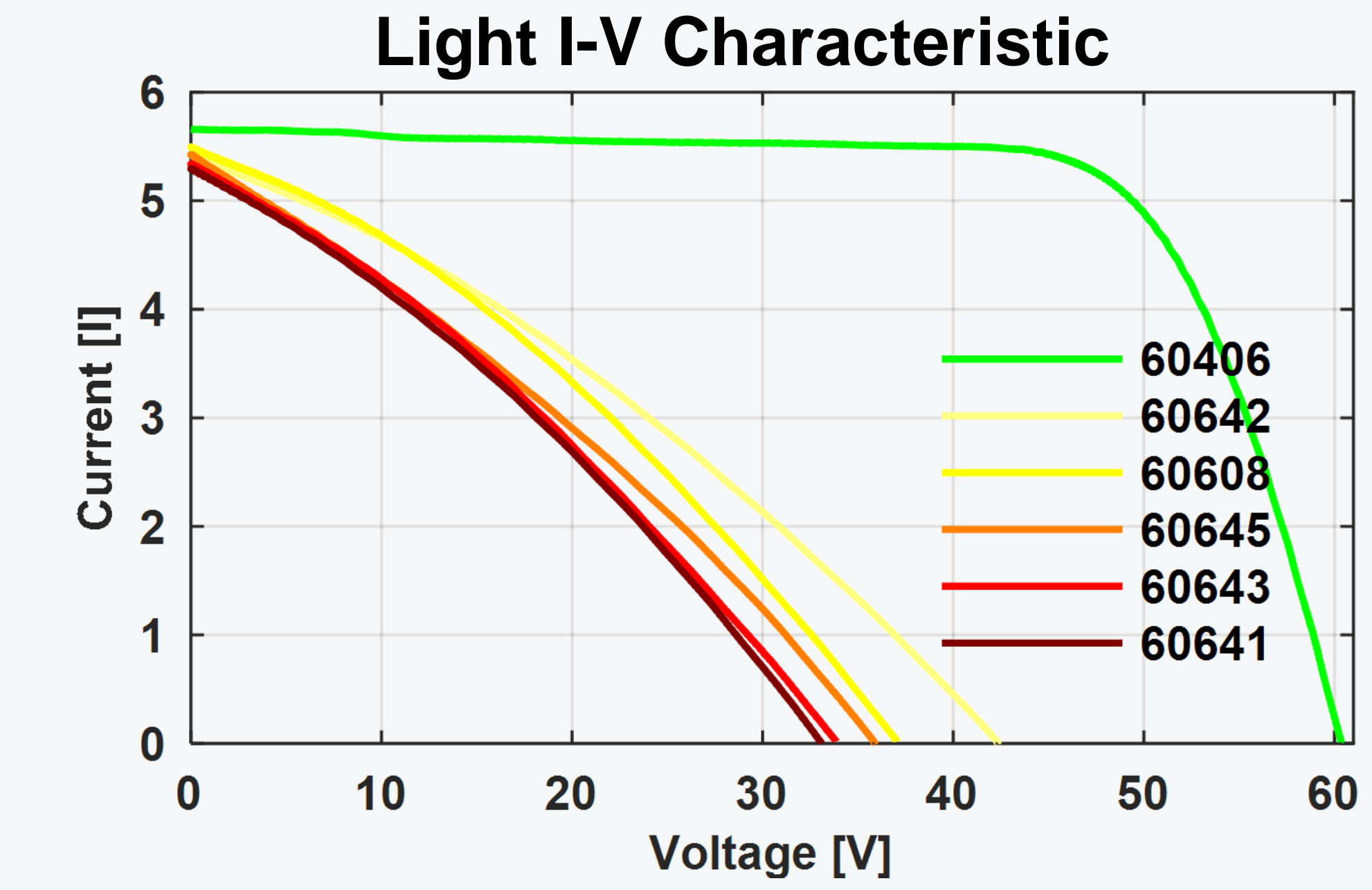
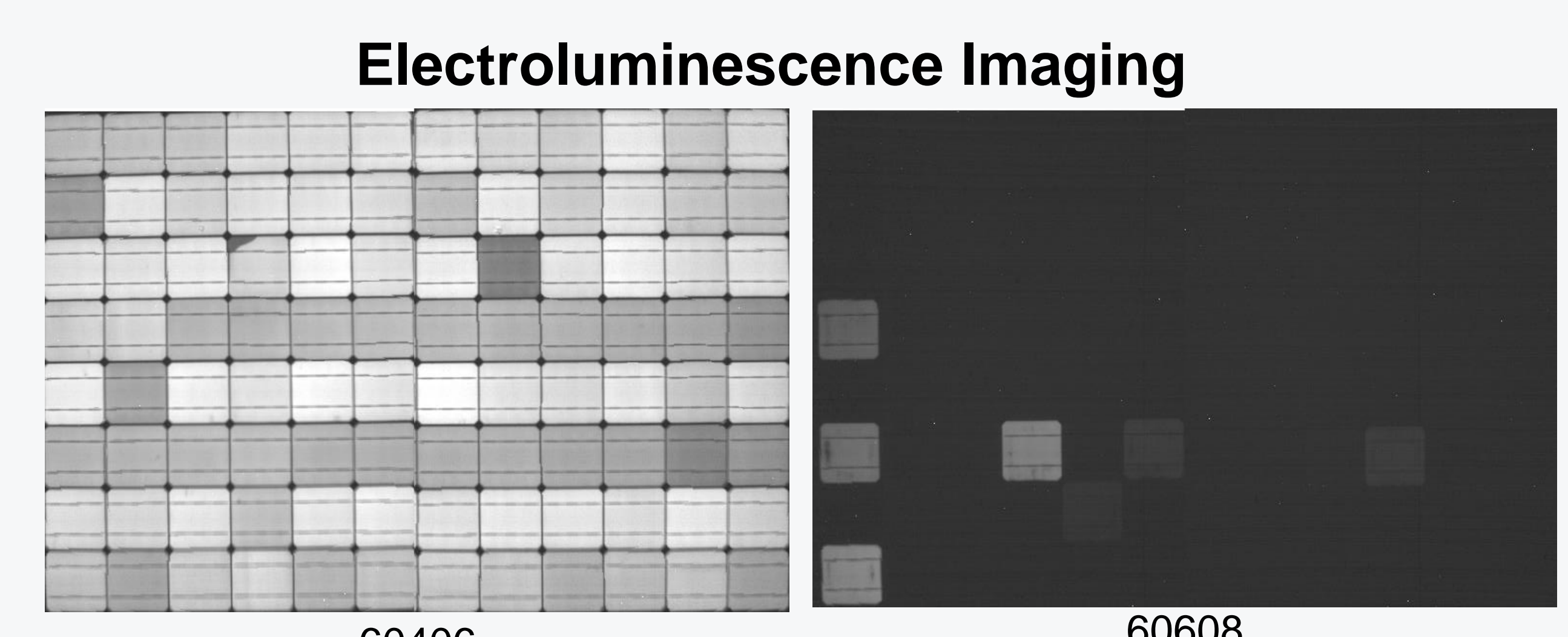

Light and dark I-V characteristics of the PV modules correlated with the EL images point out the degradation to be PID. The shunt resistance had dropped considerably.

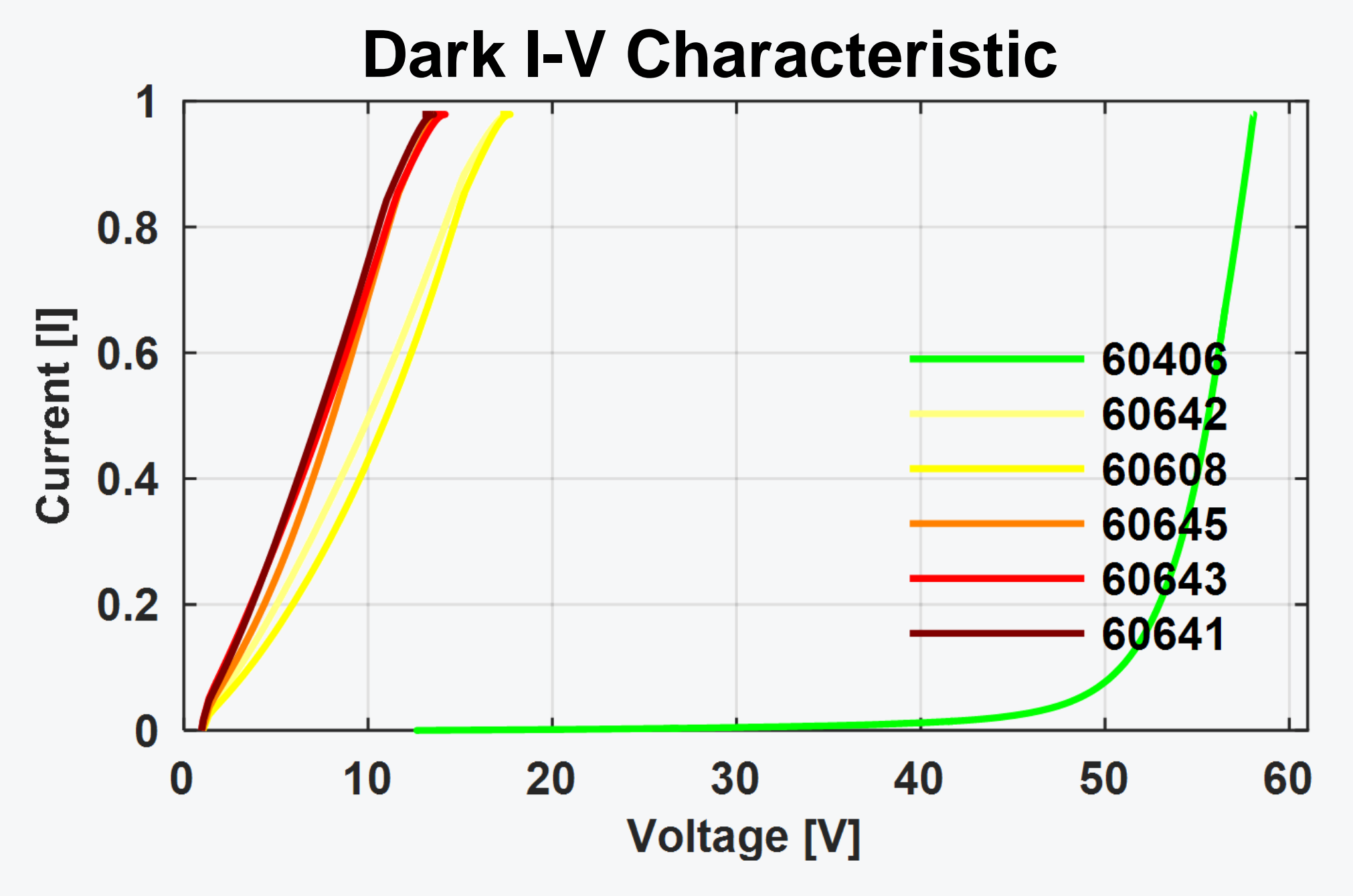

\section{IS measurements}

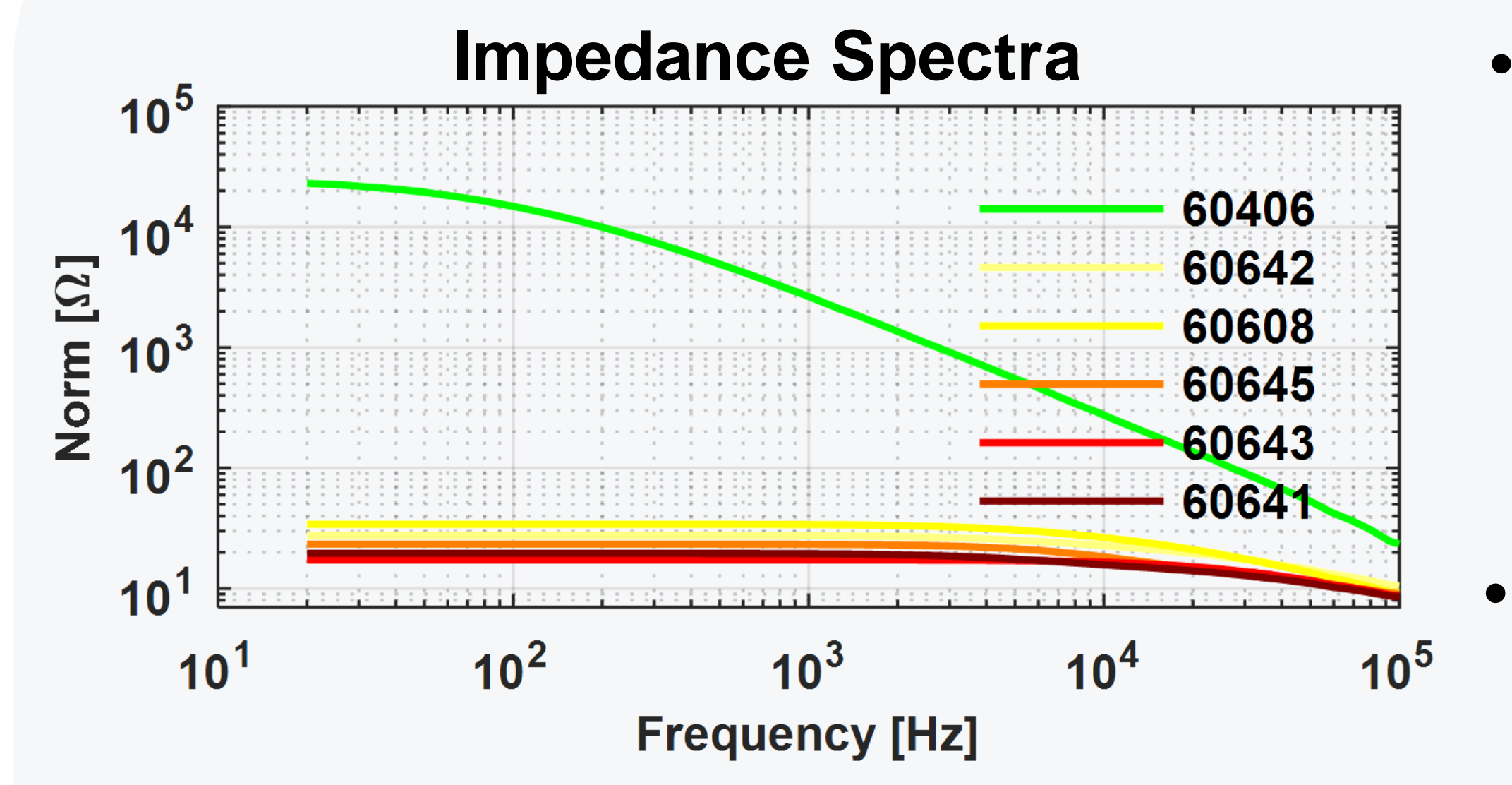

- Impedance spectra of the six PV modules, measured in dark condition in a frequency range from $20 \mathrm{~Hz}$ to $100 \mathrm{kHz}$. The difference is evident between the best performing module (60406) and the others.

Shunt resistance values determined from the IS measurements illustrate the same picture as the other characterizations. The PID modules have an $R_{p}$ much lower than the typical value for C-Si PV panels, which is around few $\mathrm{k} \Omega$.
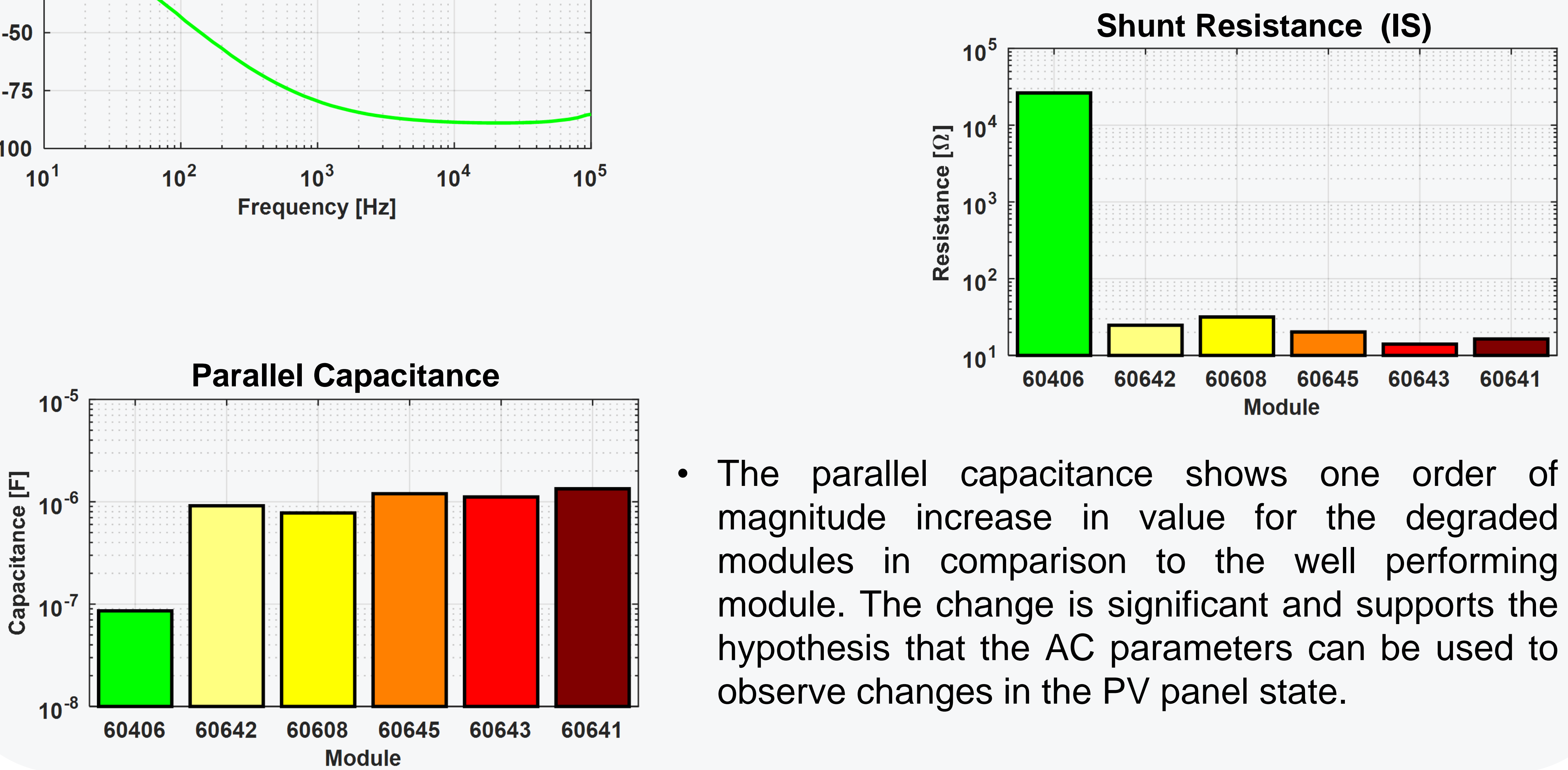

- The parallel capacitance shows one order of magnitude increase in value for the degraded modules in comparison to the well performing module. The change is significant and supports the hypothesis that the AC parameters can be used to observe changes in the PV panel state.

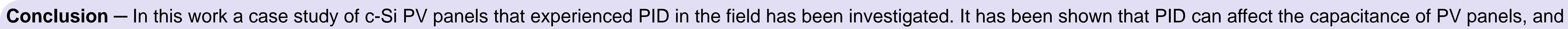

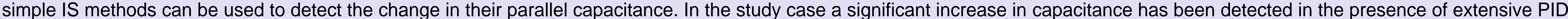

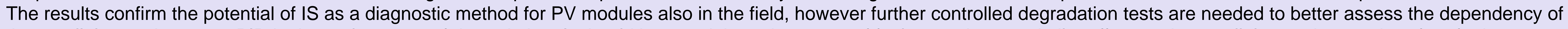

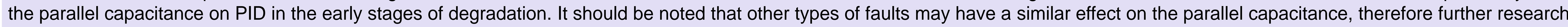
is needed for assessing the value of this parameter in presence of various faults. 